\title{
Linking foraging strategies of marine calanoid copepods to patterns of nitrogen stable isotope signatures in a mesocosm study
}

\author{
Frank Sommer ${ }^{1,3, *}$, Andrea Saage ${ }^{1}$, Barbara Santer ${ }^{2}$, Thomas Hansen ${ }^{1}$, \\ Ulrich Sommer ${ }^{1}$
}

${ }^{1}$ Leibniz-Institut für Meereswissenschaften, Experimental Ecology, Düsternbrooker Weg 20, 24105 Kiel, Germany

${ }^{2}$ Max Planck Institute for Limnology, PO Box 165, 24302 Plön, Germany

${ }^{3}$ Present address: Danish Institute for Fisheries Research, Marine Ecology and Aquaculture, Kavalergården 6, 2920 Charlottenlund, Denmark

\begin{abstract}
The foraging modes of calanoid copepods differ in that stationary suspension-feeding is more easily detected by prey with strong escape responses (ciliates) than is 'cruising' or 'ambushing' feeding. Thus, the ability of a copepod to include heterotrophic prey in its diet may be associated with its foraging mode and, further, with its nitrogen stable isotope signature $\left(\delta^{15} \mathrm{~N}\right)$. This is because a more carnivorous diet may be expected to result in a higher $\delta^{15} \mathrm{~N}$. We tested this hypothesis in a mesocosm study using a density gradient $\left(0\right.$ to 80 ind. $\left.\mathrm{l}^{-1}\right)$ of calanoid copepods. We expected copepod $\delta^{15} \mathrm{~N}$ to generally increase with decreasing copepod density because of increased food availability, and predicted stronger increases for cruising than for stationary suspension-feeding species. As an assemblage, copepods had a pronounced impact on the food web: diatoms and ciliates decreased, whereas nanoflagellates increased with increasing copepod density. As expected, Centropages hamatus, a cruising species, showed the strongest isotopic increase and also highest population growth at low copepod density, suggesting that it was the most efficient species in capturing ciliates. Temora longicornis, a stationary suspension-feeder, showed a uniform isotopic increase in all mesocosms, which we believe resulted from nutritional stress arising from poor feeding on both ciliates (too fast for ingestion by T. longicornis) and nanoflagellates (too small). However, Pseudocalanus elongatus, a species equally categorised as a stationary suspension-feeder, showed increases in its $\delta^{15} \mathrm{~N}$ similar to those for $C$. hamatus. While this may indicate potential switching in its foraging mode, alternative explanations cannot be ruled out, partly because qualitative and quantitative aspects of trophic enrichment in our experiment could not be clearly separated. This study shows that consumer $\delta^{15} \mathrm{~N}$ are difficult to interpret, even if potential food sources and aspects of the species' biology are known, and thus emphasises the necessity for further laboratory studies to help better interpret zooplankton $\delta^{15} \mathrm{~N}$ in the field.
\end{abstract}

KEY WORDS: Nitrogen stable isotopes · Trophic enrichment · Food webs · Foraging strategy · Copepods $\cdot$ Mesocosm $\cdot$ Zooplankton

\section{INTRODUCTION}

Many coastal calanoid copepods are similar in size and have similar life-history strategies, with several consecutive generations during the year (Mauchline
1998). Nutritionally, they may be best described as opportunistic omnivores feeding on both phytoplankton and heterotrophic protists (Kleppel 1993). Thus, given that many copepod species share the same temporal and spatial environment, competition for food 
may be prevalent and an important mechanism in the evolution of feeding selectivity (Mullin 1967).

Nutritional specialisation in copepods may be accomplished by specific morphological traits, e.g. differences in mouth parts (Schnack 1982) or in mechanoreceptors of the first antennae (Yen et al. 1992). Also, behavioural adaptations to different (algal) diets, e.g. the beat frequencies of feeding appendages, have been related to differences in natural diets (Vanderploeg \& Paffenhöfer 1985). Most notably though, calanoid copepods show different modes of swimming which may be associated with different diets, since swimming and feeding are inevitably linked (Greene 1988).

Based on observations and the hydrodynamic analysis of flow fields, Tiselius \& Jonsson (1990) distinguished 3 different foraging modes in calanoid copepods: (1) stationary suspension-feeding, (2) fast swimming interrupted by sinking periods ('cruise and sink' mode) and (3) motionless sinking with short jumps ('ambushing'). According to their classification, stationary suspensionfeeders, such as Temora longicornis, Pseudocalanus elongatus and Paracalanus parvus, feed primarily as herbivores. This is because they produce hydrodynamically 'loud' feeding currents, which are effective in entraining immotile phytoplankton, but less effective in capturing motile prey with strong escape responses, such as ciliates. In contrast, both cruising (e.g. Centropages typicus, C. hamatus) and ambushing (e.g. Acartia spp.) species may include a higher percentage of motile heterotrophic prey in their diet, since they forage in a hydrodynamically less 'noisy' manner.

Conclusions about copepod feeding are commonly drawn from incubation (bottle) experiments, which, however, involve major methodological problems, e.g. nutrient regeneration, crowding and lack of competition. Especially the latter aspect may contribute to the finding of similar dietary preferences for different species of copepods in bottle experiments (Poulet 1978). An alternative approach in assessing the relative contribution of autotrophic and heterotrophic prey to an animal's diet may be the measurement of nitrogen stable isotopes $\left(\delta^{15} \mathrm{~N}\right)$. This approach is based on the finding that an animal's $\delta^{15} \mathrm{~N}$ becomes increasingly enriched at each stage of trophic transfer (Minagawa \& Wada 1984), so that stronger carnivory in a species is expected to result in a higher $\delta^{15} \mathrm{~N}$ (Kling et al. 1992, Jennings et al. 2002). If, therefore, diets of copepods differ according to their feeding mode, we would expect a relatively higher $\delta^{15} \mathrm{~N}$ for a more carnivorous copepod ambushing motile (ciliate) prey than for a stationary suspension-feeding copepod filtering immotile (diatom) phytoplankton.

We tested this assumption in a mesocosm experiment, using a simple food web composed essentially of

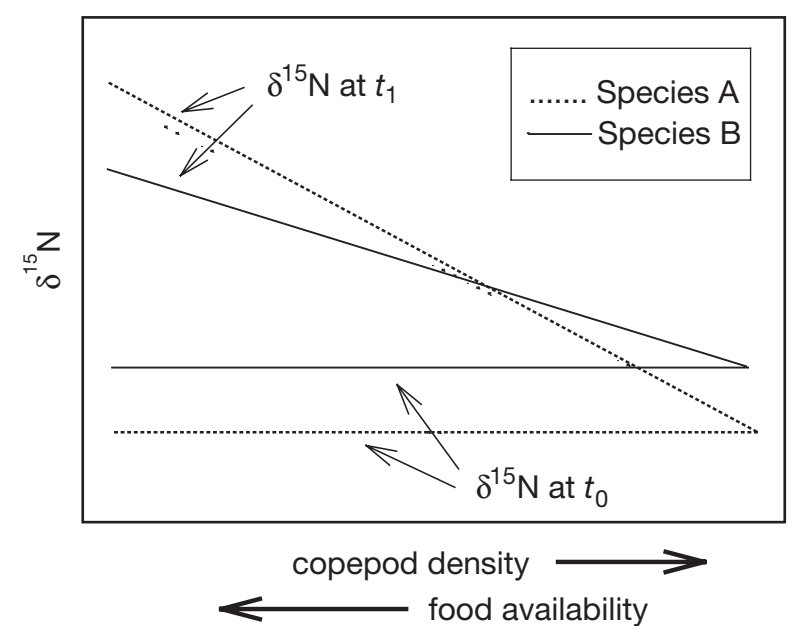

Fig. 1. Conceptual model of $\delta^{15} \mathrm{~N}$ enrichment as a function of zooplankton density. Trophic enrichment after a given time period $\left(\delta^{15} \mathrm{~N}\right.$ at $\left.t_{1}\right)$ increases with decreasing copepod density, as food becomes less limiting. Stronger carnivory results in a steeper slope (Species A) than 'more herbivorous' feeding (Species B), but not necessarily in higher $\delta^{15} \mathrm{~N}$ values at all copepod densities, since $\delta^{15} \mathrm{~N}$ enrichment occurs relative to the species' initial $\delta^{15} \mathrm{~N}\left(\delta^{15} \mathrm{~N}\right.$ at $\left.t_{0}\right)$

heterotrophic ciliates, diatoms and nanoflagellates as potential food, and a natural community of calanoid copepods. In our approach we considered 2 aspects: (1) the initial $\delta^{15} \mathrm{~N}$ of copepods, and (2) the densitydependent $\delta^{15} \mathrm{~N}$ enrichment along a copepod density gradient (Fig. 1). Initial copepod $\delta^{15} \mathrm{~N}$ would be likely to differ at the onset of the experiment due to potential differences in the species' previous diets. Consequently, $\delta^{15} \mathrm{~N}$ enrichment was considered a relative departure from the respective species' initial $\delta^{15} \mathrm{~N}$. Since tissue turnover and thus enrichment with 'heavy' $\delta^{15} \mathrm{~N}$ depends on feeding (Macko et al. 1986) and because food availability increases inversely with copepod density, copepod $\delta^{15} \mathrm{~N}$ were expected to generally increase with decreasing copepod density. Therefore, a species' degree of carnivory (i.e. the inclusion of heterotrophic prey in its diet) was inferred from the slope of a regression on $\delta^{15} \mathrm{~N}$ as a function of copepod density. We expected that the magnitude of the regression slope would depend on the copepod species' feeding mode, with less negative-slope values for stationary suspension-feeding copepods than for cruising or ambushing species.

\section{MATERIALS AND METHODS}

The mesocosm study was conducted in July 2001 in the semi-enclosed Hopavågen lagoon situated near Trondheim Fjord in central Norway (Fig. 2). This 


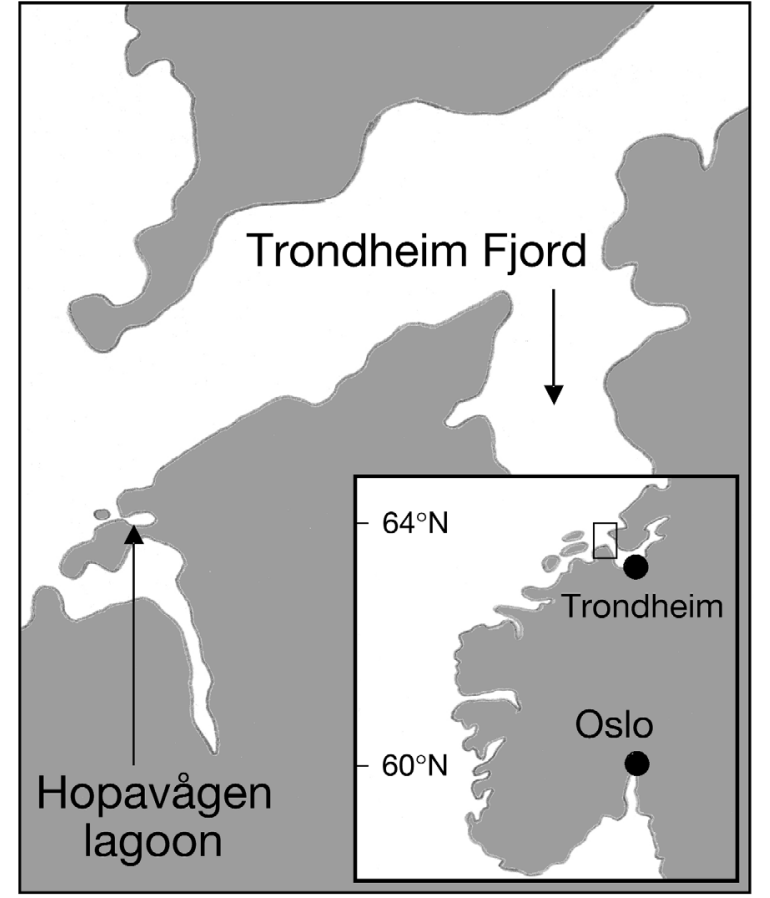

Fig. 2. Location of Hopavågen lagoon close to the outlet of Trondheim Fjord in central Norway (inset)

lagoon ( 27 ha, $32 \mathrm{~m}$ depth) is very suitable for enclosure experiments because of its sheltered geography and the fact that $\sim 14 \%$ of the water is exchanged daily through tidal forcing (Marion 1996).

The water temperature during the study period (13 to 20 July) was $\sim 13^{\circ} \mathrm{C}$. Transparent mesocosm bags $\left(1 \times 2 \mathrm{~m}\right.$ diameter $\times$ length, $\sim 1.5 \mathrm{~m}^{-3}$ enclosed water volume) were filled by hauling the submerged bags to the surface from $\sim 3 \mathrm{~m}$ depth. After filling, mesozooplankton from within the bags were removed by means of vertical hauls with a $250 \mu \mathrm{m}$ plankton net $(0.8 \mathrm{~m}$ diameter). This procedure resulted in a substantial reduction of copepods in the bags $\left(\sim 6\right.$ ind. $\left.1^{-1}\right)$ compared to ambient surface $(0$ to $3 \mathrm{~m}$ ) densities in the lagoon (55 ind. $\mathrm{l}^{-1}$ ). Copepod nauplii were reduced by $\sim 50 \%$ in the bags (10 to 18 ind. $\mathrm{l}^{-1}$ ) compared with ambient surface densities (25 ind. $\mathrm{l}^{-1}$ ).

Simultaneously, mesozooplankton-composed almost exclusively of calanoid copepods-were collected with a $250 \mu \mathrm{m}$ plankton net in the lagoon and concentrated in a plastic barrel (200 1). Dead and injured individuals were removed from the bottom of the barrel before adding copepods to the mesocosm bags in order to achieve final concentrations of 5, 10, 20, 40 and 80 ind. $\mathrm{l}^{-1}$. Densities in the highest copepod treatment (80 ind. $\mathrm{l}^{-1}$ ) were chosen to surpass the ambient copepod densities (55 ind. $\mathrm{l}^{-1}$ ) encountered in the Hopavågen. In 2 bags, vertical net hauls $(250 \mu \mathrm{m}$ mesh size, $0.8 \mathrm{~m}$ diameter) were performed daily in order to maintain these bags as completely devoid of copepods as possible throughout the study period (control treatment). All treatment densities and the control were replicated twice, resulting in 12 bags in total.

Samples for phytoplankton and ciliate counts were taken after mixing the entire enclosed water body, and fixed with a few drops of Lugol's solution. Low-precision counts of phytoplankton and ciliates in $30 \mathrm{ml}$ sediment chambers were performed daily in order to monitor plankton dynamics. Substantial differences between the seston composition in bags of different copepod densities were evident after $3 \mathrm{~d}$, with the respective positive or negative effects of copepods on different food particles remaining qualitatively the same until the end of the experiment. A detailed, indepth analysis of seston composition of samples from 19 July was performed in $100 \mathrm{ml}$ sediment chambers under an inverted microscope (Leica DM IRB) following Utermöhl (1958). The carbon content of diatoms and nanoflagellates was estimated from equations provided by Strathmann (1967), and that of ciliates calculated after Putt \& Stoecker (1989). Chlorophyll a (chl a) concentrations were determined in situ using a submersible Fluoroprobe (bbe Moldaenke).

Samples for zooplankton counts were taken with a $50 \mu \mathrm{m}$ quantitative plankton net in each bag $(0.1 \mathrm{~m}$ diameter opening, 121 sampled). Net contents were preserved in formalin ( $4 \%$ final concentration). The entire sample was counted to determine copepod densities. Population growth rates $(r)$ of copepod species were calculated as: $r\left[\mathrm{~d}^{-1}\right]=\left(\ln D_{\mathrm{a}}-\ln D_{\mathrm{b}}\right) / C_{\text {, }}$ where $D_{\mathrm{a}}$ and $D_{\mathrm{b}}$ are copepod densities on the final and initial days, respectively, and $c$ is the number of days.

Samples for the analysis of initial copepod $\delta^{15} \mathrm{~N}$ were taken from the barrel in which copepods were concentrated at the onset of the experiment on 13 July. Copepod samples for final $\delta^{15} \mathrm{~N}$ were collected with a $50 \mu \mathrm{m}$ plankton net in each bag at the end of the experiment (20 July). In order to allow for species separation, all samples were preserved in $90 \%$ ethanol. Fixation of samples with ethanol may increase zooplankton $\delta^{15} \mathrm{~N}$ (Feuchtmayer \& Grey 2003, Sommer 2003), but since our approach was based on the enrichment of zooplankton $\delta^{15} \mathrm{~N}$ relative to initial $\delta^{15} \mathrm{~N}$ (Fig. 1), and all samples were preserved alike, potential fixation effects of ethanol may be considered irrelevant in this study.

Each $\delta^{15} \mathrm{~N}$ measurement consisted of a sample of 50 to 75 copepod individuals (intact adults only) selected under a dissecting microscope and transferred to a tin cup. The initial $\delta^{15} \mathrm{~N}$ of each copepod species was determined from triplicate measurements from sam- 
ples taken in the plastic barrel. The final $\delta^{15} \mathrm{~N}$ of each species were determined from a single measurement in each mesocosm bag. After drying overnight at $40^{\circ} \mathrm{C}$, $\delta^{15} \mathrm{~N}$ samples were stored in a desiccator until combustion in a CHN-analyser (Fisons, 1500N) connected to a Finnigan Delta Plus mass spectrometer. The $\delta^{15} \mathrm{~N}$ was calculated as: $\delta^{15} \mathrm{~N}[\%]=\left[\left(R_{\text {sample }} / R_{\text {standard }}\right)-1\right] \times 1000$, where $R=\left({ }^{15} \mathrm{~N} /{ }^{14} \mathrm{~N}\right)$. Pure $\mathrm{N}_{2}$ gas was calibrated against International Atomic Energy Agency reference standards (N1, N2, N3), and a laboratory internal standard (precision of $\pm 0.2 \%$ ) was measured after every 5th sample, encompassing a range of nitrogen comparable to that of copepod samples. Regressions and statistical analyses were performed using SigmaPlot 8.0 and Statistica 6.0 software.

\section{RESULTS}

The food web in the semi-enclosed Hopavågen lagoon was composed of 3 functional groups: (1) large, immotile microphytoplankton (the diatoms Cerataulina pelagica, Leptocylindrus minimus and Guinardia delicatula), (2) large, motile heterotrophic protozoans (essentially ciliates) and (3) nanoflagellates $<5 \mu \mathrm{m}$. In terms of carbon $(\mathrm{C})$, the initial standing stock of heterotrophic ciliates was the largest group ( 31 to $110 \mu \mathrm{g} \mathrm{C}$ $\left.\mathrm{l}^{-1}\right)$, while diatoms $\left(\sim 12\right.$ to $\left.23 \mu \mathrm{g} \mathrm{C}^{-1}\right)$ and nanoflagellates $\left(\sim 14\right.$ to $\left.20 \mu \mathrm{g} \mathrm{C}^{-1}\right)$ represented similarly large $\mathrm{C}$ pools. Assuming a C content of 5 to $10 \mu \mathrm{g}$ C cope$\operatorname{pod}^{-1}$ (Mauchline 1998), copepods in the lowest (5 ind. $\mathrm{l}^{-1}$ ) and highest (80 ind. $\mathrm{l}^{-1}$ ) density treatments represented $\sim 35$ to $70 \%$ and $\sim 4$ - to 8 -fold the combined biomass of the initial standing stock of diatoms and ciliates. In most of the mesocosm bags, copepods thus represented biomass components far exceeding those of their prey.

The copepod assemblage had a strong negative impact on both diatoms and heterotrophic ciliates (Fig. 3) for all diatom species and all ciliate size classes. The C content of ciliates surpassed that of diatoms by a factor of $\sim 2$ to 6 at high and low copepod densities, respectively. Nanoflagellate biomass increased linearly with increasing copepod density and was inversely correlated with ciliate biomass (exponential regression: nanoflagellate $\mathrm{C}$

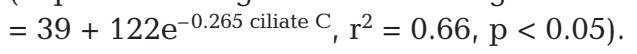
Together, these data suggest that the increase in nanoflagellates was the result of a combination of reduced grazing pressure by ciliates and nutrient regeneration by copepods. Chl a concentrations also increased linearly with increasing copepod density, and were positively linearly correlated with the concentration of

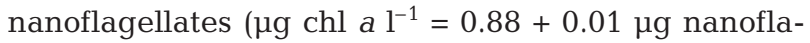
gellates $\mathrm{l}^{-1}, \mathrm{r}^{2}=0.85, \mathrm{p}<0.0001$ ), suggesting that $\mathrm{a}$ major portion of the nanoflagellates was autotrophic.

Of the 5 calanoid copepod species identified, 3 numerically dominated (>95\%) the copepod assemblage: the cruising copepod Centropagus hamatus $(\sim 20 \%)$, and Pseudocalanus elongatus $(\sim 27 \%)$ and Temora longicornis ( 48\%) which are both categorised as stationary suspension-feeders (Tiselius \& Jonsson 1990). The initial $\delta^{15} \mathrm{~N}$ of these species were 7.0, 7.7 and $6.8 \%$, respectively (Fig. 4 ; horizontal lines). Except for 1 value for $P$. elongatus, all final copepod $\delta^{15} \mathrm{~N}$ were enriched over the respective initial $\delta^{15} \mathrm{~N}$ and lay beyond the $95 \%$ confidence intervals. The difference between the initial and final $\delta^{15} \mathrm{~N}$ in mesocosm bags with the lowest copepod density was highest for C. hamatus $(\sim 1.2 \%)$, intermediate for $P$. elongatus $(\sim 0.7 \%)$ and lowest for $T$. longicornis $(\sim 0.4 \%)$. The final $\delta^{15} \mathrm{~N}$ of $C$. hamatus and P. elongatus showed a density-dependent decrease with increasing copepod densities. Linear scaling of the abscissa (copepod density) suggested a non-linear, exponential function similar to those shown for diatoms and ciliates in Fig. 3. In order to apply linear regressions, however, copepod treatment-densities were $\log _{10}$-transformed. The slope value of the linear regression was significantly larger ( $p<0.05$, test of parallelity) for C. hamatus $(-0.63)$ than

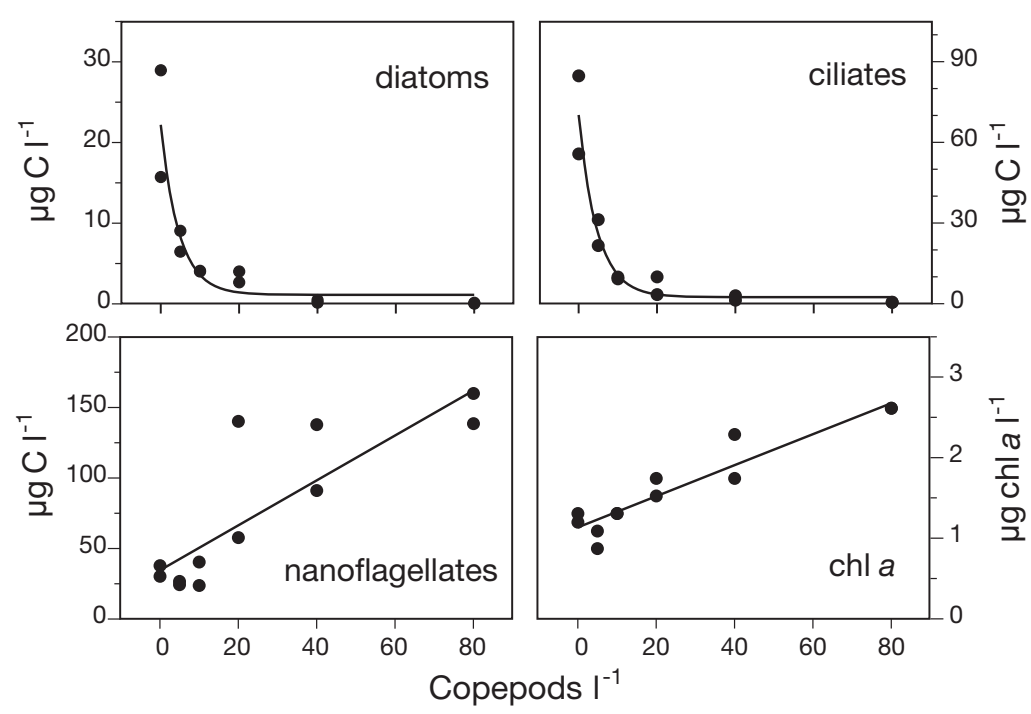

Fig. 3. Impact of copepod assemblage on major functional groups and chlorophyll a concentrations on 19 July 2001. Diatom and nanoflagellate C content was calculated according to Strathmann (1967) and that of ciliates according to Putt \& Stoecker (1989). Regressions are: diatoms: $y=1.1+21 \mathrm{e}^{-0.214 x}\left(\mathrm{r}^{2}=\right.$ $0.87, \mathrm{p}=0.0001)$; ciliates: $y=2.4+68 \mathrm{e}^{-0.210 x}\left(\mathrm{r}^{2}=0.93, \mathrm{p}<0.0001\right)$; nanoflagellates: $y=34+1.6 x\left(r^{2}=0.72, p=0.0005\right)$; chl $a: y=1.13+0.02 x\left(r^{2}=0.89\right.$, $\mathrm{p}<0.0001)$. Note different scales on ordinates 


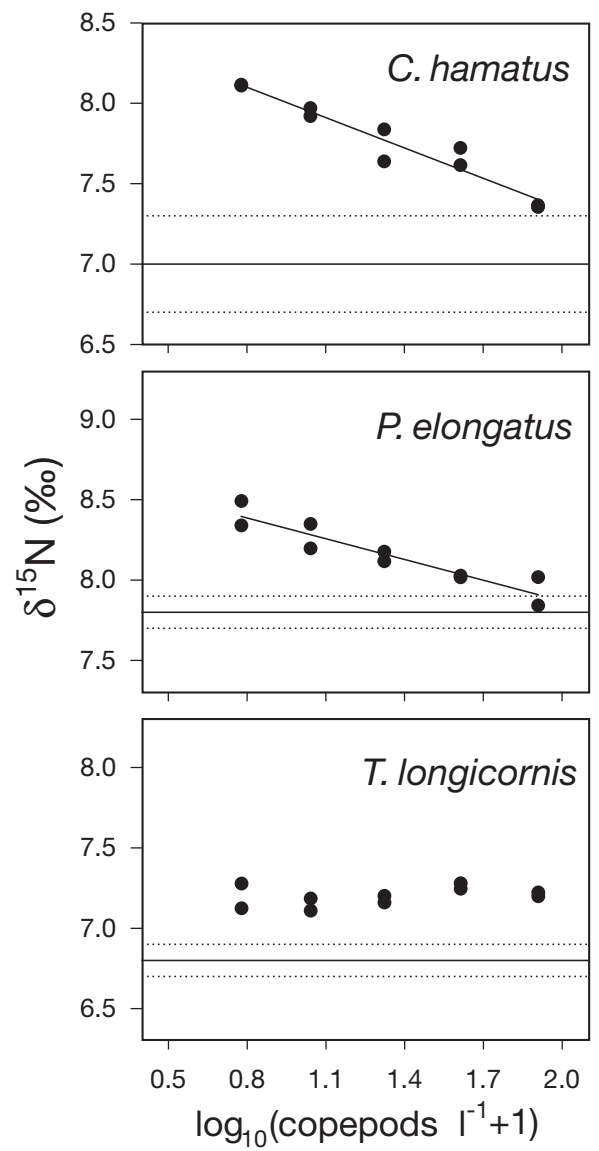

Fig. 4. Centropagus hamatus, Pseudocalanus elongatus and Temora longicornis. Final $\delta^{15} \mathrm{~N}$. Copepod densities were logarithmically transformed $\left(\log _{10}\right.$ (copepods $\left.\left.1^{-1}+1\right)\right)$ in order to apply linear regressions. Mean $\pm 95 \%$ confidence intervals of initial $\delta^{15} \mathrm{~N}(\mathrm{n}=3)$ are represented as continuous and dotted horizontal lines, respectively. Regressions are: C. hamatus: $y=8.6-0.63 x\left(\mathrm{r}^{2}=0.93, \mathrm{p}<0.0001\right) ;$. elongatus: $y=8.7-0.43 x$ $\left(r^{2}=0.87, p<0.0001\right)$. Note logarithm scale of abscissa and that ordinates are on same scale, but ranges have been selected according to initial $\delta^{15} \mathrm{~N}$ for better comparison

for P. elongatus (-0.43). For T. longicornis, the slope value was not significantly different from zero ( $\mathrm{p}>0.8)$, since all final $\delta^{15} \mathrm{~N}$ were enriched by $\sim 0.4 \%$ relative to the initial $\delta^{15} \mathrm{~N}$. Similarly, there was also a slight enrichment of the final $\delta^{15} \mathrm{~N}$ for C. hamatus $(\sim 0.3 \%$ ) and $P$. elongatus $(\sim 0.2 \%)$ in mesocosm bags with the highest copepod densities.

Centropagus hamatus showed positive population growth in all but 2 mesocosm bags (which showed zero growth), with growth rates increasing inversely to copepod density (Fig. 5). Not surprisingly, C. hamatus population growth rates were also positively correlated with the final $\delta^{15} \mathrm{~N}$ (linear regression: $\delta^{15} \mathrm{~N}[\%$ o $]=7.5+$ $\left.2.3\left[\mathrm{~d}^{-1}\right] ; \mathrm{r}^{2}=0.42, \mathrm{p}<0.05\right)$. Population growth rates of Pseudocalanus elongatus were generally positive, but showed no density-dependent relationship with cope-

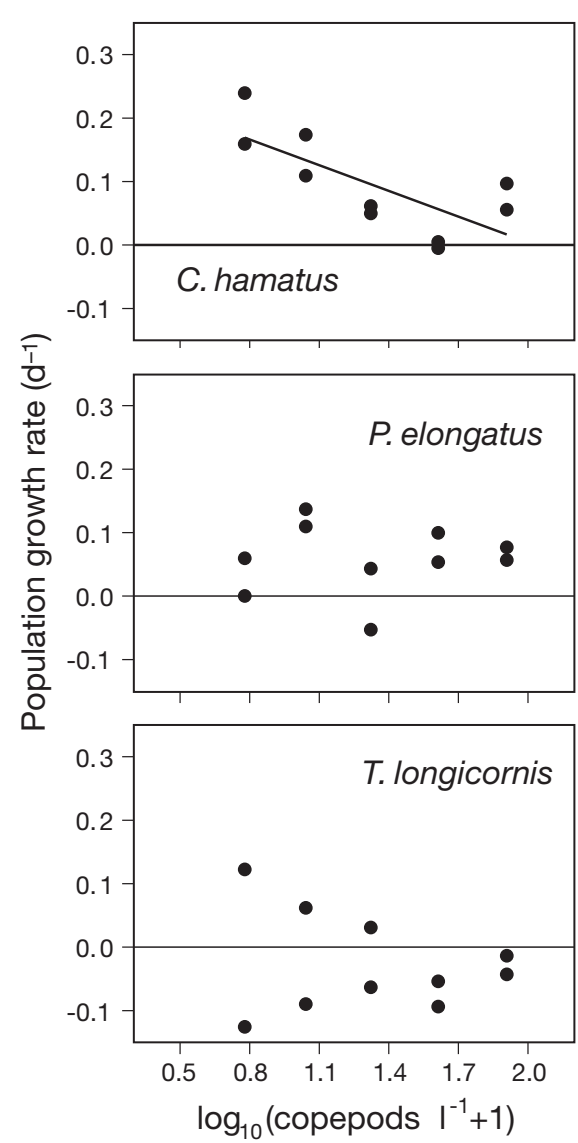

Fig. 5. Centropagus hamatus, Temoralongicornis and Pseudocalanus elongatus. Population growth rates of the 3 copepod species. Continuous horizontal lines indicate zero growth; linear regression is: $y=0.27-0.14 x\left(r^{2}=0.54, p<0.05\right)$. Note logarithm scale of abscissa

pod density. There was equally no evident relationship between Temora longicornis growth rates and treatment density. Growth rates of this species were negative at highest copepod densities, but showed pronounced variability between replicate bags at low to intermediate copepod densities.

\section{DISCUSSION}

The conceptual model in Fig. 1 was based on 2 major assumptions: (1) that trophic enrichment generally decreases with increasing copepod density due to reduced food availability (quantitative aspect), and (2) that stronger isotopic enrichment at low copepod densities results from a more carnivorous diet (qualitative aspect). Using the slope value as a measure of carnivory, we conclude that feeding on ciliates decreased in the following order Centropagus hamatus $>$ Pseudocalanus elongatus $>$ Temora longicornis, with the latter 
species being the most herbivorous. While this conclusion agrees with our expectations for $C$. hamatus, it is obviously difficult to reconcile the differences in isotopic patterns observed in $P$. elongatus and T. longicornis with the fact that both are categorised as stationary suspension-feeders (Tiselius \& Jonsson 1990). Moreover, why did $T$. longicornis show similarly enriched $\delta^{15} \mathrm{~N}$ in all mesocosms and especially in those with the highest copepod densities, in which we had expected negligible trophic enrichment?

Fig. 3 shows that the copepod assemblage significantly altered the seston composition over the experimental period, such that nanoflagellates dominated biomass at all but the lowest copepod densities. Although substantial grazing on nanoflagellates seems improbable due to their small size (Vanderploeg \& Paffenhöfer 1985, Berggreen et al. 1988), it cannot be completely ruled out that these were not ingested by copepods. Therefore, food availability cannot be considered to have become limiting per se at high copepod densities, as required by our model, making a clear separation of qualitative and quantitative aspects of trophic enrichment difficult. In the following, we will discuss each species' isotopic pattern under aspects of both quantitatively limited and unlimited food availability, and indicate alternative explanations for the observed isotopic enrichment.

Considering Centropagus hamatus first it seems most probable that the increasing isotopic enrichment with decreasing copepod density occurred due to feeding on ciliates and/or diatoms with only poor feeding on nanoflagellates. This is because $C$. hamatus shows a cruising foraging strategy best adapted to 'ambush' larger prey particles (Tiselius \& Jonsson 1990). This implies that stronger enrichment was primarily the result of a quantitatively higher ingestion, since ciliate and diatom biomass increased inversely with copepod density. Yet, even if we assume that $C$. hamatus ingested equivalent amounts of food in all mesocosms, and thus grazed nanoflagellates in mesocosms with increasing copepod densities, stronger isotopic enrichment would be equally expected at low copepod densities. This is because ciliates may be expected to have a higher (because trophically enriched) $\delta^{15} \mathrm{~N}$. Hypothetically, there remains the unlikely possibility that a high ingestion of nanoflagellates at high copepod densities was masked by low ingestion of ciliates with a high $\delta^{15} \mathrm{~N}$.

Although conceptually different, both scenarios support the view that Centropagus hamatus was the most efficient copepod species in including ciliates in its diet, since it showed the highest enrichment relative to its initial $\delta^{15} \mathrm{~N}$ at lowest copepod density. Additional support in favour of this view may be the fact that only in C. hamatus did population growth rates increase inversely with copepod density, paralleling the density-dependent enrichment of its $\delta^{15} \mathrm{~N}$. However, positive population growth does not necessarily prove that adult $C$. hamatus performed better on a ciliatedominated food web than the other copepod species. This may have also been the result of a more successful recruitment of $C$. hamatus nauplii and copepodites, which were possibly faced with a more adequate food supply than subadults of Pseudocalanus elongatus or Temora longicornis.

In terms of trophic enrichment, the similarly enriched $\delta^{15} \mathrm{~N}$ of Temora longicornis at all copepod densities implies feeding on diatoms and/or ciliates at low copepod densities and on nanoflagellates as copepod densities increased. In addition, the amounts of (nitrogen) biomass ingested would have had to be balanced in such a way that ingestion of the respective dietary sources resulted in a quantitatively comparable net enrichment of $T$. longicornis $\delta^{15} \mathrm{~N}$ at all copepod densities. This assumption has 2 implications: (1) that $T$. longicornis was the best of the 3 copepod species in exploiting nanoflagellates as a food source, because the final $\delta^{15} \mathrm{~N}$ of $T$. longicornis was highest compared with the initial $\delta^{15} \mathrm{~N}$ in mesocosms with high copepod density; (2) that feeding occurred equally on diatoms and/or ciliates at low copepod densities, although to a lesser extent than in Centropagus hamatus and Pseudocalanus elongatus based on the smaller relative enrichment of its final $\delta^{15} \mathrm{~N}$ compared with initial $\delta^{15} \mathrm{~N}$.

Switching behaviour in dependence of relative particle abundance has been investigated in detail in Acartia tonsa. This species feeds on ciliates in an ambushing mode and switches to stationary suspension-feeding when diatoms are abundant (Jonsson \& Tiselius 1990, Kiørboe et al. 1996). However, in contrast to A. tonsa, changes in Temora longicornis feeding selectivity may be achieved only by adaptations in swimming speed and beat frequency of the mouth parts (Yule \& Crisp 1983, van Duren \& Videler 1995), but not by a qualitative change of foraging behaviour (i.e. from suspension-feeding to 'cruising' or 'ambushing'). Thus, it seems reasonable to assume that $T$. longicornis maintained suspension-feeding and changed its diet in an unselective way by feeding on, possibly, diatoms (at low copepod density) and nanoflagellates (at increasing copepod densities) in proportion to their relative availability in the mesocosm bags. This would imply that $T$. longicornis was grazing at all copepod densities and may have fed largely as a herbivore, if we assume that diatoms and nanoflagellates had the same $\delta^{15} \mathrm{~N}$. This, however, raises the question why the final $\delta^{15} \mathrm{~N}$ of $T$. longicornis did not increase with increasing copepod density, given the concurrent strong increase in nanoflagellate biomass. 
Although grazing by Temora longicornis cannot be excluded, we believe that the overall, similar enrichment of $T$. longicornis $\delta^{15} \mathrm{~N}$ was more likely to have been the result of low ingestion due to an inefficiency in feeding on ciliates (too fast for capture by $T$. longicornis) and nanoflagellates (too small) at low and high copepod densities, respectively. Lack of food but also feeding on a nitrogen-deficient diet (nitrogen stress) has been demonstrated to increase zooplankton $\delta^{15} \mathrm{~N}$ to an extent $(\leq 0.4 \%$ ) (Adams \& Sterner 2000) similar to that observed in our study for T. longicornis $(\sim 0.4 \%$ ) . We further suspect that the increases in the $\delta^{15} \mathrm{~N}$ of Centropagus hamatus and Pseudocalanus elongatus at high copepod densities ( 0.2 to $0.3 \%$ ) were equally due to dietary nitrogen stress, because edible (large) food particles were scarce. However, whether because of a shortage of food or because of a diet based mainly on diatoms and nanoflagellates, T. longicornis appeared to be the most herbivorous species. A recent laboratory study supports this view, by showing that somatic growth in $T$. longicornis is optimal on a sole diatom diet and that egg production is not enhanced by the presence of ciliates (Dam \& Lopes 2003).

The similarity of isotopic enrichment in Centropagus hamatus and Pseudocalanus elongatus suggests a similar diet for both species, with the limitation that lower enrichment of $P$. elongatus $\delta^{15} \mathrm{~N}$ in mesocosms of low density may have been the result of a relatively stronger ingestion of diatoms than ciliates. An alternative explanation for the stronger enrichment of C. hamatus $\delta^{15} \mathrm{~N}$ compared with that of $P$. elongatus may be that trophic fractionation in the former species is relatively stronger, i.e. that the same diet results in a higher $\delta^{15} \mathrm{~N}$. Despite reports of species-specific $\delta^{15} \mathrm{~N}$ enrichment (Macko et al. 1982, Hart \& Lovvorn 2002), it is common practice in stable isotope studies to consider trophic fractionation to be independent of species per se ('same diet-same enrichment'). A violation of the assumption in our study would imply that slope values are indicative of species-specific enrichment rather than of true differences in diet composition. Moreover, both differences in dietary composition and species-specific enrichment may interact and could thus mask feeding on different trophic levels (e.g. if a herbivore shows higher trophic fractionation than a carnivore). This key aspect should be investigated in the future as proposed earlier by Gannes et al. (1997), since it is a prerequisite for the interpretation of trophic enrichment in any stable isotope study.

Although speculative, we believe that the most likely explanation for the observed pattern of $\delta^{15} \mathrm{~N}$ in Pseudocalanus elongatus is a switching behaviour in its foraging mode. This could explain the similarity to the pattern found for Centropagus hamatus $\delta^{15} \mathrm{~N}$, yet leaves the question open as to why population growth rates in
P. elongatus - although generally positive-did not show the same positive increase with decreasing copepod density.

It is clear from the results of this study that consumer $\delta^{15} \mathrm{~N}$ is difficult to interpret, even if the relative isotopic enrichment within a given time period, the potential food sources and aspects of the species' biology, such as foraging behaviour and morphology of the mouth parts, are known. Moreover, the food web in the Hopavågen lagoon was relatively simple, allowing inclusion of only few potential trophic links, although bundling of species into functional groups in our analysis was, of course, an additional simplification. One may question whether the gradient of copepod densities we employed may be extrapolated to natural copepod densities. Our criterion for the upper limit of the copepod density gradient was one exceeding the ambient densities in the lagoon (55 ind. $\mathrm{l}^{-1}$ ). Although it is possible that we happened to sample a highly aggregated copepod assemblage at the water surface, such high copepod densities are no unusual phenomenon in this bay at this time of the year (I. Gismervik pers. comm.). Thus, it is not clear, whether isotopic enrichment resulting from starvation is a relevant factor when considering stable isotope signatures from field samples.

Taking only the relative enrichment in mesocosms with the lowest copepod densities into account, it increased in the order Temora longicornis < Pseudocalanus elongatus < Centropagus hamatus, suggesting an increase in carnivory in the same order. This result is qualitatively identical to that achieved by our approach using the slope value as an indicator of carnivory. However, if we consider the initial $\delta^{15} \mathrm{~N}$ in absolute terms (as it is traditionally done), we find increasingly higher $\delta^{15} \mathrm{~N}$ in the order T. longicornis < $C$. hamatus $<P$. elongatus, implying the strongest degree of carnivory in $P$. elongatus. Similar variability in the $\delta^{15} \mathrm{~N}$, with no consistent pattern between species or functional groups, was also found in a recent field study on natural zooplankton $\delta^{15} \mathrm{~N}$ by Sommer \& Sommer (2004). Together, these data clearly demonstrate that more laboratory studies are necessary in order to better interpret isotopic data from field samples. Such studies should focus on aspects of trophic enrichment (including the importance of species-specific enrichment), consumer and food density and potential plasticity in feeding behaviour.

Acknowledgements. We thank the European Commission's Programme 'Improving Human Potential-Access to Research Infrastructures' for financial support and access to infrastructures, and Ø. Leiknes, N. Tokle and A. Neyts for help in Norway. Help from members of the Institute for Marine Research, Kiel, and Max Planck Institute of Limnology, Plön, during field work is acknowledged. We are grate- 
ful to T. Kiørboe, P. Tiselius and 3 anonymous reviewers for valuable comments on earlier versions of the manuscript. This is a contribution to the DFG-project SO 145/19-1.

\section{LITERATURE CITED}

Adams TS, Sterner RW (2000) The effect of dietary nitrogen content on trophic level $\delta^{15} \mathrm{~N}$ enrichment. Limnol Oceanogr 45:601-607

Berggreen U, Hansen B, Kiørboe T (1988) Food size spectra, ingestion and growth of the copepod Acartia tonsa during development: implications for determination of copepod production. Mar Biol 99:341-352

Dam HG, Lopes RM (2003) Omnivory in the calanoid copepod Temora longicornis: feeding, egg production and egg hatching rates. J Exp Mar Biol Ecol 292:119-137

Feuchtmayr H, Grey J (2003) Effect of preparation and preservation procedures on carbon and nitrogen stable isotope determinations from zooplankton. Rapid Commun Mass Spectrom 17:2605-2610

Gannes LZ, O'Brien D M, Martínez del Rio C (1997) Stable isotopes in animal ecology: assumptions, caveats, and a call for more laboratory experiments. Ecology 78: $1271-1276$

Greene CH (1988) Foraging tactics and prey-selection patterns of omnivorous and carnivorous calanoid copepods. Hydrobiologia 167:295-302

Hart EA, Lovvorn JR (2002) Interpreting stable isotopes from macroinvertebrate foodwebs in saline wetlands. Limnol Oceanogr 47:580-584

Jennings S, Pinnegar JK, Polunin NVC, Warr KJ (2002) Linking size-based and trophic analyses of benthic community structure. Mar Ecol Prog Ser 226:77-85

Jonsson PR, Tiselius P (1990) Feeding behaviour, prey detection and capture efficiency of the copepod Acartia tonsa feeding on planktonic ciliates. Mar Ecol Prog Ser 60:35-44

Kiørboe T, Saiz E, Viitasalo M (1996) Prey switching behaviour in the planktonic copepod Acartia tonsa. Mar Ecol Prog Ser 143:65-75

Kleppel GS (1993) On the diets of calanoid copepods. Mar Ecol Prog Ser 99:183-195

Kling GW, Fry B, O'Brien WJ (1992) Stable isotopes and planktonic trophic structure in arctic lakes. Ecology 73: 561-566

Macko SA, Lee WY, Parker PL (1982) Nitrogen and carbon isotope fractionation by two species of marine amphipods: laboratory and field studies. J Exp Mar Biol Ecol 63:145-149

Macko SA, Fogel Estep ML, Engel MH, Hare PE (1986) Kinetic fractionation of stable nitrogen isotopes during amino acid transamination. Geochim Cosmochim Acta 50: $2143-2146$

Editorial responsibility: Otto Kinne (Editor-in-Chief), Oldendorf/Luhe, Germany
Marion P van (1996) Ecological studies in Hogavågen, a landlocked bay at Agdenes, Sør-Trøndelag, Norway. Gunneria 71:1-39

Mauchline J (1998) The biology of calanoid copepods. In: Blaxter JHS, Southward AJ, Tyler PA (eds) Advances in marine biology, Vol 33. Academic Press, New York

Minagawa M, Wada E (1984) Stepwise enrichment of ${ }^{15} \mathrm{~N}$ along food chains: further evidence and the relation between $\delta^{15} \mathrm{~N}$ and animal age. Geochim Cosmochim Acta 48:1135-1140

Mullin MM (1967) On the feeding behavior of planktonic marine copepods and the separation of their ecological niches. Proceedings of Symposium on Crustacea. Marine Biological Association of India, Madras, p 955-964

Poulet SA (1978) Comparison between five coexisting species of marine copepods feeding on naturally occurring particulate matter. Limnol Oceanogr 23:1126-1143

Putt M, Stoecker D (1989) An experimentally determined carbon:volume ratio of marine 'oligotrichous' ciliates from estuarine and coastal waters. Limnol Oceanogr 34: $1097-1103$

Schnack SB (1982) The structure of the mouthparts of copepods in Kiel Bay. Meeresforschung 29:89-101

Sommer F (2003) A comparison of the impact of major mesozooplankton taxa on marine, brackish and freshwater phytoplankton during summer. $\mathrm{PhD}$ thesis, Ber Inst Meereskd Christian-Albrechts-Univ Kiel

Sommer F, Sommer U (2004) $\delta^{15} \mathrm{~N}$ signatures of marine mesozooplankton and seston size fractions in Kiel Fjord, Baltic Sea. J Plankton Res 26:495-500

Strathmann RR (1967) Estimating the organic carbon content of phytoplankton from cell volume or plasma volume. Limnol Oceanogr 12:411-418

Tiselius P, Jonsson PR (1990) Foraging behaviour of six calanoid copepods: observations and hydrodynamic analysis. Mar Ecol Prog Ser 66:23-33

Utermöhl H (1958) Zur Vervollkommnung der qualitativen Phytoplankton-Methodik. Mitt Int Theor Angew Limnol 9:1-38

Vanderploeg HA, Paffenhöfer GA (1985) Modes of algal capture by the freshwater copepod Diaptomus sicilis and their relation to food-size selection. Limnol Oceanogr 30:871-885

van Duren LA, Videler JJ (1995) Swimming behaviour of developmental stages of the calanoid copepod Temora longicornis at different food concentrations. Mar Ecol Prog Ser 126:153-161

Yen J, Lenz PH, Gassie DV, Hartline DK (1992) Mechanoreception in marine copepods: electrophysical studies on the first antennae. J Plankton Res 14:459-512

Yule AB, Crisp DJ (1983) A study of feeding behaviour in Temora longicornis (Müller) (Crustacea: Copepoda). J Exp Mar Biol Ecol 71:271-282

Submitted: February 3, 2004; Accepted: September 30, 2004 Proofs received from author(s): January 26, 2005 